\title{
Evidence of accelerated and altered pollen development after Imazapyr treatment in resistant sunflower
}

\author{
Ana Claudia Ochogavía ${ }^{1,2 \star}$ (D) , Marta Beatríz Bianchi²,3 (D), Liliana Picardi²,3 (D), Graciela María Nestares ${ }^{12}$ (D) \\ 1. Instituto de Investigaciones en Ciencias Agrarias de Rosario - Genética de la Resistencia a Herbicidas en Cultivos - \\ Zavalla (Santa Fe) Argentina. \\ 2. Universidad Nacional de Rosario - Facultad de Ciencias Agrarias - Zavalla (Santa Fe) Argentina. \\ 3.Consejo de Investigaciones de la Universidad Nacional de Rosario - Facultad de Ciencias Agrarias - Zavalla (Santa Fe), Argentina
}

\begin{abstract}
Imazapyr (IM) treatment applied at early reproductive developmental stages have been associated with induced male sterility in sunflower (Helianthus annuus L.). The aim of this work was to determine the effects induced by two different doses of IM-treatment (1X and 2X; 80 and $160 \mathrm{~g}$ a.i. ha ${ }^{-1}$ ) on pollen grain yield, pollen viability and on the exine surface, in an intermediate resistant (I) and a completely resistant (R) genotype. An anatomical analysis of some stages during the microsporogenesis and microgametogenesis was also achieved by confocal microscopy. Plants of both genotypes survived the herbicide treatments and showed no external injury symptoms. Differential response to different doses of IM was obtained in R and I genotypes. The pollen grains per flower and the viability in seeds were significantly reduced in the I genotype by the $2 X$ treatment; however, the pollen viability of the remaining grains was not altered, and the diameter of the pollen grains was increased by the herbicide treatment. Anatomical and cytological observations of the sporogenous tissue development were made via confocal microscopy. IM treatment induced alterations in sporogenous cells during the initial phases of microsporogenesis in both genotypes, and the $2 X$ dose accelerated the microgametogenesis process, particularly in the I genotype. These findings improved the understanding of the mechanism underlying the gametocide effects of the imidazolinones in sunflower.
\end{abstract}

Key words: induced male-sterility, confocal microscopy, herbicide resistance, Helianthus annuus L.
Received:

27 Aug 2019

Accepted:

17 Dec 2019

Section Editor:

Gabriel Constantino Blain

${ }^{*}$ Correspondence author:

anaochogavia@conicet.gov.ar

\section{INTRODUCTION}

Sunflower (Helianthus annuus L.) is the second most important crop in the world, based on hybrid breeding, only behind maize (Seiler et al. 2017). Weeds cause yield losses ranging from 20 to $70 \%$, and the control of broadleaf weeds in sunflower - a broadleaf crop - is especially difficult (Sala et al. 2012; Castaño 2018). Herbicide-resistant cultivars offer an efficient technical solution to solve this problem. In sunflower, Imisun cultivars were the first commercial imidazolinoneresistant genotypes (Miller and Al-Khatib 2002; Sala et al. 2012). Herbicide resistance in these cultivars has been reported to be controlled by a major gene, known as Imr1 or Ahasl1-1, and a modifier gene (Imr2) (Kolkman et al. 2004; Sala et al. 2012). Im $r 1$ or Ahasl1-1 is a resistance allele at the Ahasl 1 locus, one of the three acetohydroxyacid synthase (AHAS; EC 4.1.3.18) coding genes (Kolkman et al. 2004). The AHAS enzyme, also known as acetolactate synthase (ALS), catalyzes the first step in the biosynthetic pathway of the branched chain amino acids (BCAA). A mechanism related to nontargetsite resistance was associated to Imr2 (Breccia et al. 2017; Balabanova et al. 2018). 
The herbicide-resistance trait might provide not only an efficient way to control weeds in crop production, but it could also be a promising alternative for evaluating combining ability in breeding programs. Male sterility induced by chemical hybridization agents offers an interesting pollination control system that allows almost any inbred line with desirable traits to be used as a female parent in test cross evaluation to asses combining ability. Tibenuron methyl (TBM) is one of the most commonly used AHASinhibitory hybridization agents. Recently published work has associated sublethal TBM treatment with alterations occurred during microsporogenesis in susceptible rapeseed lines, suggesting AHAS as the target of chemical agents that induce male sterility (Zhao et al. 2015). These authors have hypothesized that foliar-sprayed TBM is polar-transported to anthers and inhibits the AHAS enzyme, resulting in BCAA starvation and the autophagic cell death in anthers, which ultimately leads to male sterility. Around this hypothesis, novel TBM-resistant rapeseed mutants have just been developed. This fact allows relating the TBM-induced male sterility with the AHAS activity pattern in a modified logistic function (Lv et al. 2017). In sunflower, Sala et al. (2012) described IM-induced male sterility during the early reproductive development stages in imidazolinone resistant lines. Recently, a study by Ochogavía et al. (2018) have provided evidence of morphological, cytoembryological, and molecular alterations in the reproductive tissue in 'Imisun' sunflower lines. It was demonstrated that the field recommended dose of imazapyr affects the female and male reproductive development, reducing the pollen grain number and finally the seed production. The treatment also alters the expression patterns of the ahas anther genes during early reproductive stages in sunflower (Ochogavía et al. 2018).

In the present study, the effects of different doses of imazapyr on the development of the pollen formation of two Imisun genotypes differing in the presence of the modifier resistance gene, Imr2, were analyzed. The objectives of this investigation were (i) to elucidate the effects induced by two different IM doses in early reproductive developmental stages in resistance sunflower during the development of the pollen sac and (ii) to identify possible association between the effect of the IM treatment and the presence of the Imr2. To address these objectives, pollen yield, pollen viability, pollen diameter and exine surface structure were analyzed. In addition, the anatomical analysis of some stages during the microsporogenesis and microgametogenesis was achieved by confocal microscopy, and the male reproductive tissue development in peripheral and in central flowers at different stages after treatment was compared.

\section{MATERIAL AND METHODS Plant materials and growth condition.}

The complete imidazolinone-resistant HA425 (R, Imr1 Imr1 Imr2 Imr2) and the intermediate resistant 1058-1 (I, Imr1 Imr1 imr2 imr2) 'Imisun' inbred sunflower lines were used in this study (Miller and Al-Khatib 2002), and the imidazolinone susceptible line, HA89 (imr1 imr1 imr2 imr2) (Bruniard and Miller 2001).

Sunflower plants were grown at the Experimental Field Station of the Instituto de Investigaciones en Ciencias Agrarias de Rosario in Zavalla, Santa Fe, Argentina ( $33^{\circ} 1^{\prime} S$; $60^{\circ} 53^{\prime} \mathrm{W}$ ) in a completely randomized design with six replications of 20 plants each. Weeds were manually controlled without the use of agrochemicals. The commercial herbicide imazapyr (IM) \{2-[(RS)-4-isopropil-4-metil-5-oxo-2-imidazolin-2-il] nicotinic acid (Clearsol, BASF) $\}$ was applied at two different rates: the recommended dose (1X: $80 \mathrm{~g}$ a.i. $\mathrm{ha}^{-1}$ ) and twice the recommended dose (2X: $160 \mathrm{~g}$ a.i.ha ${ }^{-1}$ ), when plants reach the R1 (early reproductive) developmental stage (Schneiter and Miller 1981). The control groups consisted of untreated plants of $\mathrm{R}$ and I genotypes. The environmental variables recorded at the application time are detailed in the Supplementary Table (ESM1). To check the successful herbicide application, the susceptible HA89 line was also treated with both doses. Sunflower inflorescences were covered with pollination bags to keep insects out to avoid cross-pollination. Field experiments were carried out during the $2017 / 2018$ season.

\section{Number of pollen grains per flower}

The number of pollen grains per flower was counted with a hemocytometer on five closed flowers (E1 phenophase). A pollen grains suspension was made and analyzed under stereomicroscope as described by Ochogavía et al. (2018). 


\section{Pollen grain diameter determination}

Pollen grains were analyzed by differential interference contrast (DIC) microscopy as described by Ochogavía et al. (2018). Anthers of five flowers of three different treated plants (i.e., IM-1X, IM-2X, and the control of each genotype) were clarified using the Herr's solution (Herr Jr., 1971). A Leica DM2500 microscope equipped with a digital camera was used. Diameters of ten pollen grains excluding the exine layer per flower $(\mathrm{n}=600)$ were measured using ImageJ software (Abramoff et al., 2004).

\section{Pollen viability}

Fresh pollen was collected during E3 phenophase (anther dehiscence period (Schneiter and Miller 1981) and treated with lactophenol and $0.01 \%$ aniline blue (W/V) (Maneval 1936). The percentage of viable pollen grains was estimated as described by Ochogavía et al. 2018).

\section{Confocal microscopy analysis of the sporogenous tissue}

Flower buds were collected from three capitula per treatment combination of R and I genotypes (RC, RT1X, RT2X, IC, IT1X, and IT2X) at 11 and 16 days after treatment (11 and 16 DAT). Flowers were immediately fixed in modified FAA (Lersten and Curtis 1988) and dissected under a binocular stereomicroscope. Anthers were dissected, clarified, and analyzed under confocal microscopy following Ochogavía et al. (2018) (C1plus confocal on a Nikon TE2000 E2 inverted microscope). equipped with $40 \mathrm{~mW}$ Melles Griot argon ion laser and a 525/50 emission filter. Micrographs were acquired using Nikon EZ-C1 (v 3.9) software.

\section{Scanning electron microscopy of pollen grains}

Mature pollen grains from $2 \mathrm{X}$ treated and control plants of $\mathrm{R}$ and I genotypes were collected after anthesis and immediately fixed in modified FAA (Lersten and Curtis 1988). Samples were incubated in ethanol ( $96 \% \mathrm{v} / \mathrm{v})$ for $12 \mathrm{~h}$ and dehydrated during $12 \mathrm{~h}$. Dehydrated pollen was mounted on SEM stubs using double-sided carbon tape, coated with gold layer using an ion sputter (Emitech sputter coater) and observed in a Leitz AMR-1000 scanning electron microscope.

\section{Filled seed count}

One hundred seeds per plant from five treated (1X and 2X) and control plants of each genotype were analyzed by hand as was described by Ochogavía et al. (2018). The percentage of filled seeds was verified and recorded $(\mathrm{n}=3000)$.

\section{Statistical analysis}

Assumptions of normality and homogeneity of variance of the empirical distribution were assessed by Shapiro-Wilk and Levene's tests. The means comparisons between treated and control plants of the PGF and pollen grain diameters were performed by the t-test using the R software v.3.0.0 (R Development Core Team, 2010). The statistical comparisons between treated and control percentages of pollen viability and filled seeds were assessed by the Chi-square test.

\section{RESULTS}

Treated plants of HA425 (R) and 1058-1 (I) genotypes did not show a substantial chlorosis or necrosis in leaves or buds, and they achieved flowering at the same date as the control plants. No differences in the capitula morphology and development were detected at 11 and 16 days after treatment among treatments (DAT) of the R (Fig. 1a-f) and I 
(Fig. 1g-1) genotypes. The 2X IM treatment induced mild symptoms of chlorosis in the edge of apical leaves during the first days after treatments both in R (Fig. 1 c) and in I (Fig. 1 i) genotypes, but this fact was suddenly reverted (Fig. 1, panels $\mathrm{f}$ and $\mathrm{l}$ ). On the other hand, the susceptible line (HA89) was significantly affected by both $1 \mathrm{X}$ and $2 \mathrm{X}$ IM treatments (Fig. 1m-r). All treated plants of this genotype showed dehydration symptoms $24 \mathrm{~h}$ after application date of the $1 \mathrm{X}$ IM dose and $12 \mathrm{~h}$ after application of the $2 \mathrm{X}$ dose. Dehydrated plants presented necrosis symptoms in the apical meristem region, and they finally died 20 DAT (Fig. 1n, o, q, and r).

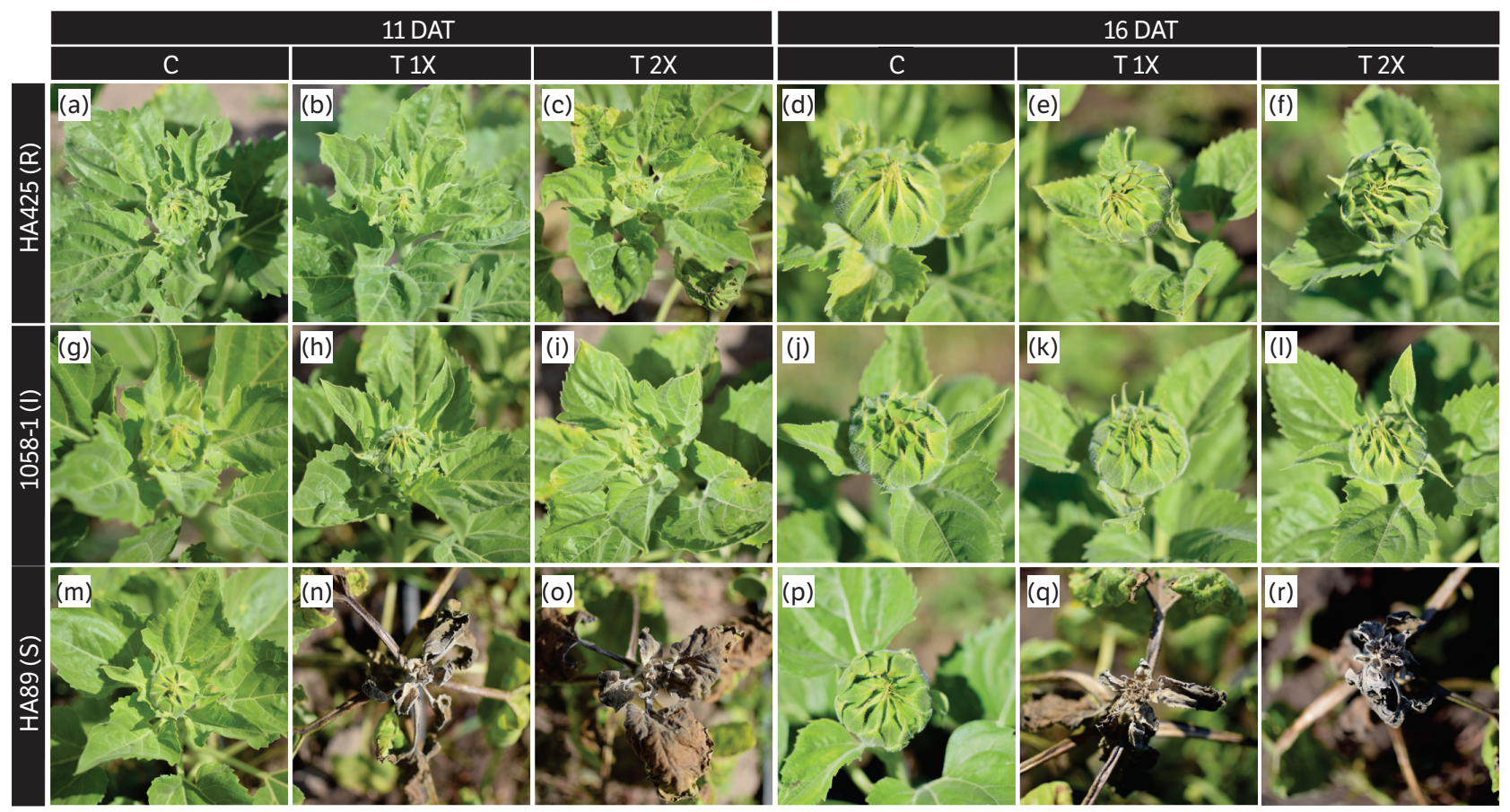

Note: Plants of the imidazolinone complete resistant genotype (R) are showed in panels a to f. Slightly chlorosis effect of the $2 X-I M$-treatment was evidenced in the leaves edge at 11 DAT (c) but it was reverted at 16 DAT (f). R control (a); R 1X IM-treated plants (b); and R 2X IM-treated plants (c), I control (d) I 1X IM-treated plants (e); and R 2X IM-treated plants (f), and HA89 (Imidazolinone susceptible) 1X (g) and 2X IM-treated plants (H).

Figure 1. Effect of $1 X$ and $2 X$ imazapyr treatment on genotypes HA425 (R), 1058-1 (I) and HA89 (imidazolinone susceptible genotype; S) in the field at 11 and 16 days after treatment (DAT).

The number of pollen grains per flower (PGF) was evaluated in R and I genotypes treated with $1 \mathrm{X}$ and $2 \mathrm{X}$ doses of imazapyr (Table 1). A significant decrease in PGF of treated plants of the I genotype was detected, but nonsignificant differences were observed among treatments in the R genotype ( $\mathrm{p}>0.05$ ). Control plants from I genotype produced $24 \%$ increased PGF than the $1 \mathrm{X}$-treatedplants $(\mathrm{p}<0.05)$ and $31 \%$ over the $2 \mathrm{X}$-treated plants $(\mathrm{p}<0.01)$. The pollen viability remained at similar levels for $\mathrm{R}$ and I genotypes ( 87.65 and $88.28 \%$, respectively), and nonsignificant differences were detected between treatments $\left(\mathrm{X}^{2}=0.03 ; \mathrm{p}=0.83\right)$ (see Table 1 ).

Significant higher diameter means of the pollen grains were found when comparing each herbicide treatment (1X and $2 \mathrm{X}$ doses) with control plants from I genotype ( $\mathrm{p}=0.02$ and $\mathrm{p}=0.0001$, respectively, Table 1$)$. However, for the $R$ genotype pollen diameters of $1 X$ treated plants did not differ from control $(p=0.09)$, while a significant increase was verified between control and $2 \mathrm{X}$ treated plants $\left(\mathrm{p}=1.3 \mathrm{e}^{-5}\right.$; Table 1$)$.

Microscopic studies confirm that each anther of $H$. annuus L. consists of four pollen sacs with synchronous development (Baghali et al. 2011). Pollen development followed the basic scheme in Asteraceae, as the primary sporogenous cells developed directly in microsporocytes (microspore mother cell) from which the microspore tetrads were produced by meiosis. Microspores development from the two neighboring microsporangia were synchronized. The comparison of IM treatments (1X and 2X) and control effects on pollen development was achieved by confocal laser microscopy. 
Anthesis of successive series of buds in the sunflower capitula occurs centripetally, as a consequence of being peripheral flowers phenologically advanced in comparison with the central ones. By observing flower buds from the center of the disc comparing young anthers (11 DAT) with the control, altered primary sporogenous cells were not identified (Fig. 2a, c, e, g, i and k). It was also possible to visualize cells in meiosis both in treated and control plants.

The first abnormalities in anthers of IM-treated plants were detected at the peripheral flower buds of the same disc. The microspore mother cells could be recognized easily, but dark "holes" were detected at the pollen sac region in both treated genotypes (indicated by the arrowheads in Fig. $2 \mathrm{f}, \mathrm{h}$ and $\mathrm{j}$ ). Images of the same optical slides obtained by DIC microscopy confirmed that the epidermis and endothecium layer were intact, so the absence of cells inside the pollen

Table 1. Pollen and seed variables of inbred lines HA425 and 1058-1 of Helianthus annuus L under different IM treatments (1X, 2X and 0).

\begin{tabular}{|c|c|c|c|c|c|}
\hline \multirow[b]{2}{*}{ Genotype } & \multirow[b]{2}{*}{ IM-Treatments } & \multicolumn{3}{|c|}{ Pollen variables } & \multirow{2}{*}{$\begin{array}{c}\text { Seed variable } \\
\text { Filled seeds (\%) }\end{array}$} \\
\hline & & $\begin{array}{c}\text { Pollen grains per } \\
\text { flower }\end{array}$ & $\begin{array}{l}\text { Pollen viability } \\
\text { (\%) }\end{array}$ & $\begin{array}{l}\text { Pollen diameter } \\
(\mu \mathrm{m})\end{array}$ & \\
\hline \multirow{3}{*}{$\begin{array}{l}\text { IMI-Resistant genotype } \\
\text { (HA425) }\end{array}$} & 0 (control) & $23998 \pm 3450$ & 87.65 & $33.175 \pm 254$ & 93.89 \\
\hline & $1 X$ & $24412 \pm 1933$ & 89.43 & $32.592 \pm 186$ & 95.01 \\
\hline & $2 X$ & $21045 \pm 1822$ & 85.69 & $34.173 \pm 152^{\star \star}$ & $45.66^{\star \star}$ \\
\hline \multirow{3}{*}{$\begin{array}{l}\text { IMI- Intermediate resistant } \\
\text { genotype (1058-1) }\end{array}$} & 0 (control) & $20966 \pm 2212$ & 88.28 & $31.387 \pm 174$ & 84.99 \\
\hline & $1 X$ & $15926 \pm 1678^{\star}$ & 92.37 & $32.065 \pm 213^{\star}$ & 72.20 * \\
\hline & $2 X$ & $14466 \pm 2411^{*}$ & 91.67 & $33.791 \pm 173^{\star \star}$ & 47.08 ** \\
\hline
\end{tabular}

Significant differences respect to the control: * $\mathrm{p}<0.05 ;{ }^{* *} \mathrm{p}<0.01$.
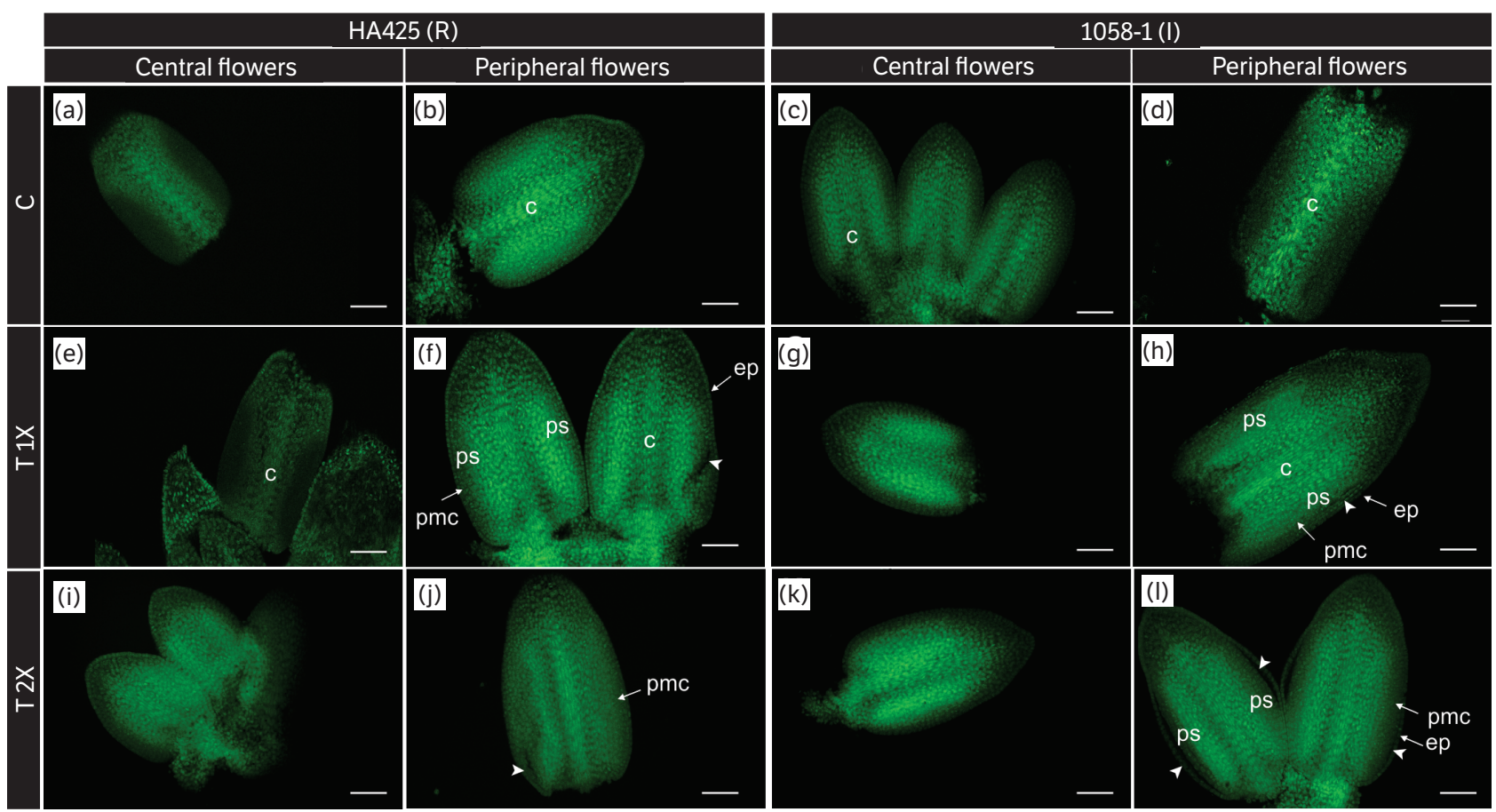

Note: Panels a-d. Untreated plants of R ( $a$ and b) and I (c and d) genotypes. Panels E-H. 1X IM-treated plants of R (e and f) and I ( $g$ and h) genotypes. Panels I-L. 2X IM-treated plants of R ( $\mathrm{a}$ and $\mathrm{j}$ ) and I ( $\mathrm{k}$ and I) genotypes. Dark 'holes', suggesting sporogenous tissue damage, are signaled at the pollen sac region in both treated genotypes (indicated by the arrowheads in panels $\mathrm{f}$, j, and h). DIC micrographs (ESM2) confirm intact epidermis and endothecium layer. Detachment between the endothecium and the epidermis, detected only in the treated I genotype, are also indicated by the arrowheads (Panel $\mathrm{h}$ and I). Abbreviations: c connective tissue of the filament; ep epidermis; pmc primary mother cells; ps pollen sac. Scale bars = 50 $\mu \mathrm{m}$.

Figure 2. Confocal laser scanning micrographs of immature anthers collected 11 days after IM-treatments (1X and 2X) of HA425(R) and 1058-1(I) genotypes. Confocal green fluorescence (488nm line from a $40 \mathrm{~mW}$ Melles Griot argon ion laser and a 525/50 emission filter) of anthers from two different regions of the capitula (internal flowers and peripheral flowers) were compared among treatments and genotypes. 
sac evidenced sporogenous tissue damage (ESM2). It was also noticed that the $160 \mathrm{~g}$ a.i. $\mathrm{ha}^{-1}$ IM treatment induced a detachment between the endothecium and the epidermis layer but only in the I genotype anthers (indicated by the arrowheads in Fig.2 1).

Wide variability during the development of pollen grains was visualized in anthers of 16 days after treatment, and substantial alterations were detected in treated plants of the R (Fig. 3e, f, i and j) and I (Fig. 3g, h, k, and l) genotypes. IM treatment clearly induced an accelerated development of the pollen. Both control and treated anthers of central flowers of the R genotype were in the initial phases of microsporogenesis, and the treatment did not alter its development (Fig. 3a, e and i). However, treated anthers of peripheral flower buds were accelerated in their development respect to the control ones (Fig. 3b, f and j). The tetrahedral microspores tetrads (Fig. 3j) and microspores released (Fig. 3f) were detected in both $2 \mathrm{X}$ and $1 \mathrm{X}$ treated plants, respectively. In the intermediate resistant genotype (I), the pollen grain development was highly affected in treated anthers. While microspore mother cells were detected in the sporangia of central flowers from control plants, the microsporocytes were already formed in the treated ones (Fig. 3c, $g$ and $\mathrm{k}$ ). The alterations of the sporogenous tissue were also detected in the internal flower buds for $2 \mathrm{X}$ treatment (indicated by arrowheads in Fig. 3k). In the Fig. 3k, the magnified section of the theca shows one of several disorganized regions. Some dark "holes" were distinguishable in the tissue, suggesting that the pollen mother cells do not follow a normal pattern of division, observed in the control plants, and hence a regular structure of the tetrahedral tetrad. As expected, the confocal optical sections of the peripheral flowers of the $2 \mathrm{X}$ treated plants show a reduced number of pollen grains (Fig. 31).

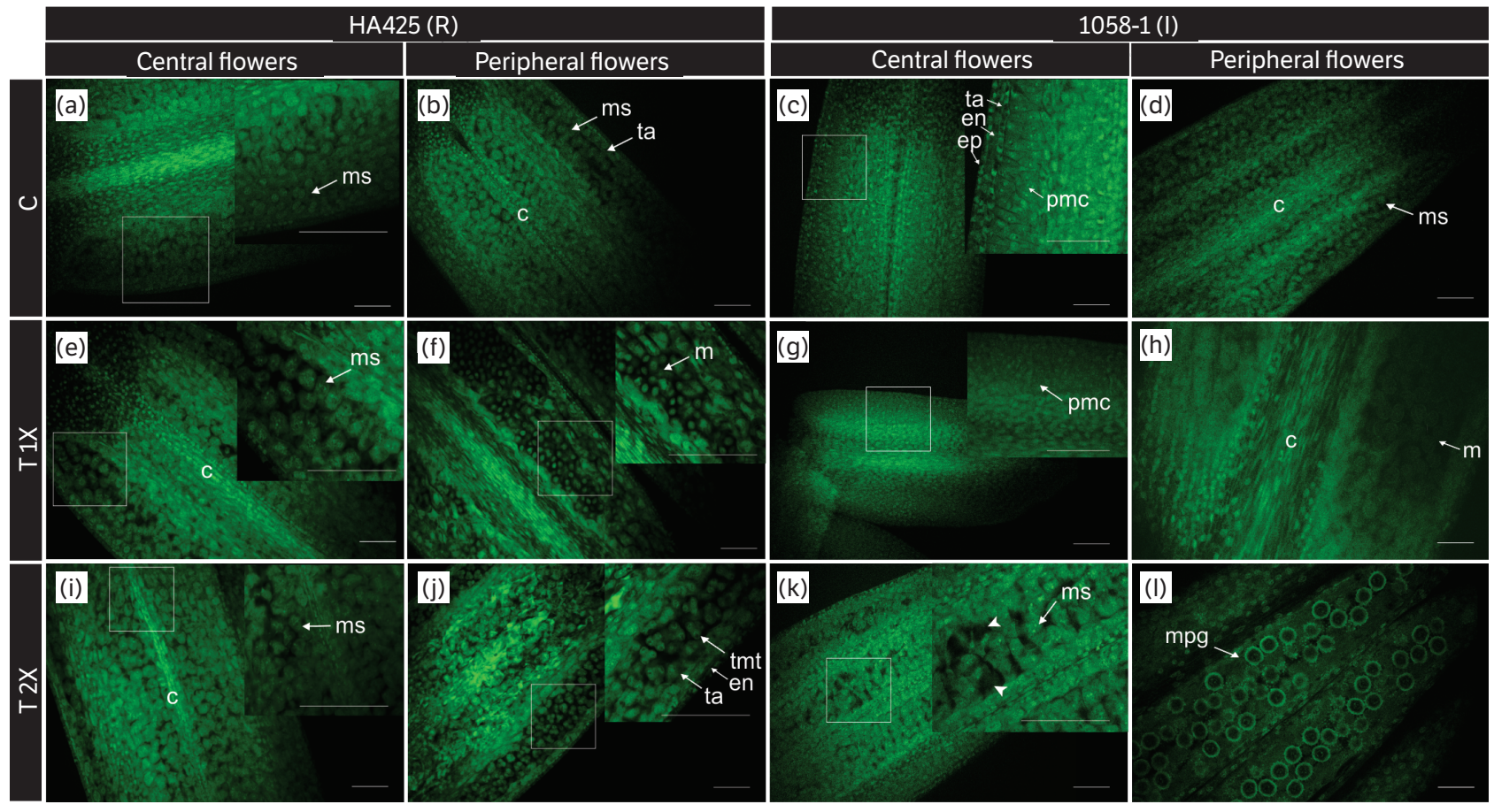

Note: Confocal green fluorescence (488nm line from a 40mW Melles Griot argon ion laser and a 525/50 emission filter) of anthers from two different regions of the capitula (internal flowers and peripheral flowers) were compared among treatments and genotypes. Internal images represent the magnified view of the squared region (zoom 4X). Panels a-d. Untreated plants of R ( $a$ and b) and I (c and d) genotypes. Panels E-H. 1X IM-treated plants of R (e and f) and $\mathrm{I}(\mathrm{g}$ and $\mathrm{h}$ ) genotypes. Panels I-L. 2X IM-treated plants of R ( $\mathrm{I}$ and $\mathrm{j}$ ) and I ( $\mathrm{k}$ and $\mathrm{I}$ ) genotypes. Alterations of the microsporogenesis in the central flowers of genotype I after $2 X$ doses are signaled (Fig. 3, panel k). The magnified section of the theca showed one of several disorganized regions that do not follow a normal pattern of division and hence a regular structure of the tetrahedral tetrad generating dark "holes" (arrowhead). Panel I. Peripheral flowers with not abundant pollen grains indicate that the empty spaces are associated with the sporogenous tissue alterations or a reduced number of tetrahedral tetrads and/or microsporocytes in treated plants. Abbreviations: c connective tissue of the filament; en endothecium; ep epidermis; $\mathrm{m}$ microspores; ms microsporocytes; $\mathrm{mpg}$ mature pollen grains; pmc primary mother cells; ta tapetum layer; tmt tetrahedral microspore tetrads. Scale bars $=50$ $4 \mathrm{~m}$.

Figure 3. Confocal laser scanning micrographs of immature anthers collected 16 days after IM-treatments (1X and $2 X)$ of HA425(R) and 1058-1(I) genotypes. 
In the external flowers of the same capitula, a clear association between the increased herbicide doses and the developmental stage was evidenced. When control and treated plants were compared for immature anthers collected 16 days after IM treatments, an advanced development of pollen formation was observed in the latter. While the control plants showed that the microsporangium was in microsporogenesis, anthers of plants treated with $80 \mathrm{~g}$ a.i. $\mathrm{ha}^{-1} \mathrm{of} \mathrm{imazapyr} \mathrm{were}^{-1}$ in microgametogenesis, and mature pollen grains were detected in plants treated with $160 \mathrm{~g}$ a.i.ha ${ }^{-1}$ (Fig. $3 \mathrm{~d}, \mathrm{~h}$, and l).

The pollen shape and characteristics of the exine surface were analyzed by SEM microscopy (Fig. 4). No significant differences in the spines sculpturing, spine abundance, and pore diameter were detected between $2 \mathrm{X}$ IMI-treated and control plants from both genotypes. Turgid pollen grains were identified with cytoplasm projections arising from the germ pores in both treated and control plants (Fig. 4).

Regarding the effect of the IM treatment on viable seed production, significantly lower seed set percentages were observed in 2X IM-treated plants with respect to control ones from $\mathrm{R}$ and I genotypes $\left(\mathrm{X}^{2}=110.3 \mathrm{p}<0.0001\right.$, and $\mathrm{X}^{2}=54.5 \mathrm{p}<0.0001$, respectively). The single dose (1X) of imazapyr significantly reduced the number of viable seeds but only in the I genotype $\left(\mathrm{X}^{2}=3.96 \mathrm{p}<0.04\right)$, suggesting a restricted response of the R genotype to the $1 \mathrm{X}$ IM treatment (Table 1).
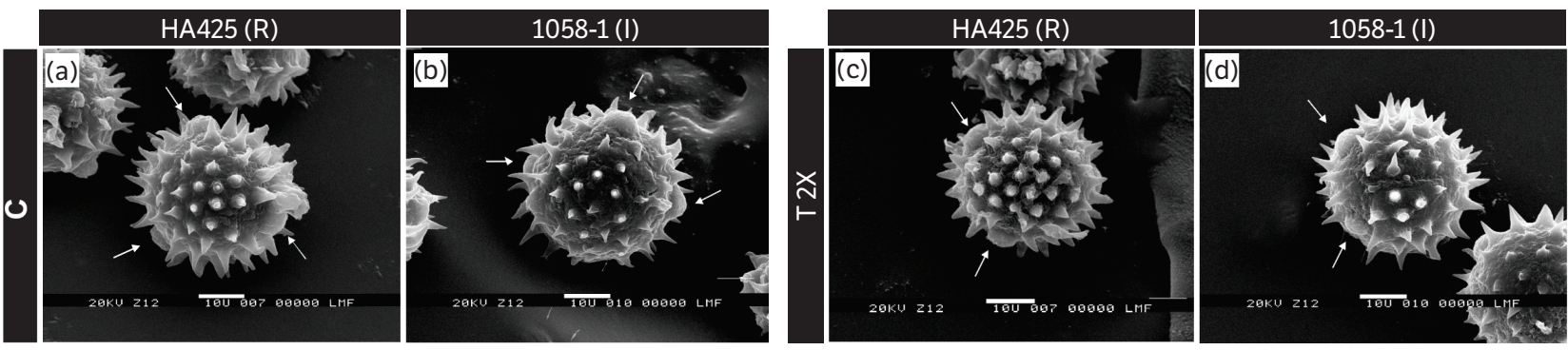

Note: Pollen grains were observed in a Leitz AMR-1000 scanning electron microscope. The spherical shaped and exine structure of pollen grains is not altered by the treatment. The arrows indicate the normal pore apertures from hydrated pollen grains. Scale bars $=10 \mu \mathrm{m}$.

Figure 4. Scanning electron micrographs of mature pollen grains from 2X Imazapyr treated and control plants of HA425(R) and 1058-1(I) genotypes.

\section{DISCUSSION}

In a previous work, morphological, cytoembryological, and AHAS-genes expression alterations induced by IM-treatment during the female and male gametophyte development in 'Imisun' sunflowers ( $R$ and I genotypes) were described (Ochogavía et al., 2018). A biochemical/metabolic pathway analogous to rapeseed has been proposed for this species. Evidence of tissue-specific and Imr2 gene-dependent response has been also reported. Recommended field rates of imazapyr (1X) applied at early reproductive growth stages trigger significant variations in the expression patterns of the ahas genes almost exclusively in the anthers, and signals of sporogenous tissue alterations have been detected in the intermediate resistant sunflower genotype (Ochogavía et al. 2018).

In the present study, the effects of two different doses of imazapyr (1X and $2 \mathrm{X}$ ) on the pollen physiology and morphology, seed production, and during selected stages of the microsporogenesis and microgametogenesis processes in 'Imisun' sunflowers were evaluated. In the field, both 'Imisun' genotypes did not show any substantial herbicidal effect in leaves or flowering development at the evaluated doses induced by the IM-treatment. The PGF was significantly reduced by IM-treatment in the I genotype, as the $1 \mathrm{X}$ and the $2 \mathrm{X}$ treated plants had 24 and $31 \%$ less PGF than control plants, respectively. However, nonsignificant reduction of this variable was detected among treatments for the $\mathrm{R}$ genotype, even for the $2 \mathrm{X}$ dose. Nevertheless, the viability of the remaining pollen was high in treated plants of both genotypes. 
The present results are consistent with previous work where pollen yield has been reduced in a 23\% in $1 \mathrm{X}$ treated plants of the intermediate resistant genotype (I) (Ochogavía et al. 2018). Reduction in pollen yield, mainly in the $2 \mathrm{X}$ dose, suggests that the gametocide effect of the herbicide treatment occurs during the initial phases of microsporogenesis. The diminution in PGF was only observed in the I genotype, and damaged microsporocytes and a detached epidermis layer in anthers of this genotype were actually detected. In this sense, the empty spaces should be associated with the sporogenous tissue alterations or a reduced number of tetrahedral tetrads and/or microsporocytes in treated plants. This result reinforces the hypothesis that the herbicide induces alterations in the initial phases of the microsporogenesis. Unexpectedly, dark areas corresponding to the "holes" in the sporogenous tissue were also observed in early developed anthers of the R genotype. During normal pollen grain development, there is an enlargement of the microgametophytes; also, the interior of the microsporangium is occupied by the disorganized tapetum cells (Pacini et al. 1985).

Underlying molecular bases of the cytocidal effects of sublethal doses of the AHAS inhibiting herbicides has been studied specially in susceptible rapeseed and Arabidopsis (Quian et al. 2011; Li et al. 2015, Liu et al. 2017). Authors have suggested that herbicides induce BCAA starvation and block the carbohydrate and lipid metabolism, leading to chloroplasts destruction and autophagic cell death in anthers (Quian et al. 2011; Li et al. 2015, Zhao et al. 2015; Liu et al. 2017, Lv et al. 2018).

The induced male sterility has been related with the diminution in AHAS activity in Brassica napus, confirming that AHAS is the main target of the AHAS-inhibiting herbicide TBM when is used as chemical hybridization agent (Lv et al. 2018). However, recently published results indicated that the inhibition of AHAS activity is necessary but not enough for TBM to induce male sterility (Lian et al. 2019). Metabolic pathways related to lipid metabolism, pollen exine formation, photosynthesis and hormone response have been associated with male sterility induced by sublethal doses of TBM in TBMsusceptible rapeseed (Lian et al. 2019).

Authors have reported an abnormal callose layer in the tetrahedral tetrad microspores of treated plants that finally induces irregular pollen wall construction. A significant reduction in the pollen grain number of resistant treated sunflower plants in this study. However, no differences in the tetrahedral tetrad microspores stage neither in the exine subphase were evidenced, by confocal or SEM analysis. In sunflower, the enzyme pool in reproductive tissue has the lowest contribution of the AHAS1 isoform, that is coded by the paralog that contains mutations conferring resistance (Ochogavía et al. 2014). Therefore, in these tissues the AHAS pool enzyme is inhibited in the presence of the Imazapyr herbicide, even in the 'Imisun' resistant genotypes. Other resistance mechanisms may be causing a reduction in the amount of herbicide molecules reaching their target and thus restricting the effects on pollen wall construction.

The herbicide resistance in the I genotype is a result of target-site resistance (Imr1 Imr1 imr2 imr2), while in the R genotype it is a combination of target-site and nontarget-site resistance (Imr1 Imr1 Imr2 Imr2) (Kolkman et al. 2004). Target-site resistance is based on single mutations in one of the AHAS coding gene (ahas1) which modified the site of action of AHASinhibiting herbicides (Kolkman et al. 2004, Sala et al. 2012). Recently published reports have associated the nontarget-site resistance with increased herbicide detoxification by $\mathrm{P} 450$ monooxygenases isozymes and glutathione S-transferases in sunflower (Breccia et al. 2017, Balabanova et al. 2018). The authors of this work hypothesize that the detoxification effect contributed by the Imr2 gene reduced the number of molecules of herbicide that reach the AHAS in anthers, limiting the alterations induced by the $2 \mathrm{X}$ treatment in the R genotype plants.

In hermaphrodite plants, the mean of the number of pollen grains per flower (PGF) and the pollen/ovule ratio have a direct correspondence with the breeding system and have consequences on seed set (Cruden 1977; Burd 1994). The IM-induced PGF reduction has an adverse effect on the pollen/ovule ratio in the I genotype, so it is expected that it negatively affects the seed production. In this genotype, herbicide treatment reduced viable seeds in a 15 and $45 \%$ for $1 \mathrm{X}$ and the $2 \mathrm{X}$-treated plants, respectively. Nonetheless, the reduction of the PGF would not be the only causal of the diminution of the seed set since the $2 \mathrm{X}$ treatment did not affect the PGF but reduced the viable seeds in the R genotype (52.3\%). It suggests that the IM treatment would reduce the viable seed set involving different molecular mechanisms in the evaluated genotypes.

The results of this work also demonstrated that IM treatment induces an accelerated development of pollen grains and a significant increase in their diameters, especially in the I genotype. Confocal microscope observations at 16 DAT revealed that microspores and mature pollen grains were detected in anthers of $1 \mathrm{X}$ and $2 \mathrm{X}$ treated plants, respectively, while in 
control plants only microsporocytes were found. Nonetheless, IM-induced accelerated development would not affect pollen viability. The analysis of pollen diameter by DIC microscopy allowed to detect significantly higher means of pollen grains from $\mathrm{R}$ and I plants treated with $2 \mathrm{X}$ doses, and only in I plants treated with $1 \mathrm{X}$ doses.

Limited studies on sunflower embryology both at light as well as electron microscope levels have studied the microsporogenesis and microgametogenesis (Horner Jr. 1977; Laveau et al. 1989; Baghali et al. 2011). The important role of the tapetum layer cells in pollen development has been reported. The tapetum is formed by large cells rich in nutrients that provide nutritional substances for the developing microspores and pollen wall, and they are gradually digested during maturation of pollen grains (Horner Jr. 1977). The beginning of the tapetum degeneration is also variable among families or even genus, especially in ameboid tapetum type as in Helianthus annuus, in which tapetum degeneration only begins after the first haploid mitosis division of the microspores has taken place (Horner Jr. and Pearson 1978). The pollen grain development and growth are inhibited by the formation of exine in plants, but when exine is not regularly formed this inhibition may fail, and the pollen grains continue to grow.

Recently, the effects of benzo(a)pyrene (BaP) treatment on the formation and development of pollen grains and its proteins in sunflower has been elucidated. BaP-treated plants delayed the degeneration of the tapetum layer in anthers, with a consequent formation of giant and irregular pollen grains with a lower germination index (Baghali et al. 2011). In this study, the significant enlargement of the pollen grains might be associated with abnormal function of the tapetum layer induced by the imazapyr treatment. However, the pollen viability and the exine surface were not significantly affected, so, additional physiological processes, as megagametophyte alterations, could be reducing the seed production in the R genotype. Further analysis of the imazapyr effects on the female gametophyte and embryo development should be done to discard abortive effects induced by the herbicide treatment.

\section{CONCLUSION}

This comprehensive study identified that the alterations were induced by the two different doses of IM treatment during the microsporogenesis in both 'Imisun' genotypes. Furthermore, R and I genotypes have a differential response to the herbicide treatments as the partial male-sterility was only detected in the intermediate resistant genotype (Imr 1 Imr1 imr2 imr2).

The effects of the herbicide imazapyr applied in the early reproductive stage accelerates the microsporangia development in resistant genotypes, i.e., the formation of tetrahedral microspore tetrads, the beginning of microgametogenesis, and the pollen grain maturation displayed faster in treated versus control plants. Interestingly, similar effects induced on the embryo-sac development by 1 X IM treatment have been reported in a previous work.

The IM treatment constitutes an external stress that stimulates the gametogenesis in both reproductive tissues. The authors of this work strongly believe that the understanding of histological and developmental intricacies of microsporogenesis in IM-treated resistant plants will throw light on the causes of the decrease of pollen grains per flower and seed production.

Overall, these findings showed a number of anomalous events induced by the herbicide treatment on the genesis of microspores and also during the development of pollen grains, especially at twice field recommended dose (2X). These findings confirm the gametocidal effect of this imidazolinone herbicide and the feasibility to use it as chemical hybridization agent.

\section{ACKNOWLEDGEMENTS}

Thanks are due to Dr. Jerry Miller and to Dr. José María Bruniard for kindly gift of seed materials. The authors also thank to Dr. Fernando López-Anido for his valuable assessment in the field experiments; and to Prof. José Pellegrino and Dr. Enrique Sanchez Pozzi for their kind assistance in the confocal microscopy analysis. 


\section{FUNDING}

Fondo para la Investigación Científica y Tecnológica

[https://doi.org/10.13039/501100006668]

Grant \# PICT 20131010 and PICT 20161316

Consejo Nacional de Investigaciones Científicas y Técnicas

[https://doi.org/10.13039/501100002923]

Grant \# P-UE 22920160100043

\section{AUTHORS' CONTRIBUTION}

Conceptualization, Ochogavía A. C., Bianchi M. B. and Nestares G. M.; Methodology, Ochogavía A. C. and Nestares G. M.; Investigation, Ochogavía A. C., Bianchi M. B. and Nestares G. M.; Writing - Original Draft, Ochogavía A. C.; Writing - Review and Editing, Bianchi M. B., Picardi L., and Nestares G.M.; Funding Acquisition, Nestares G. M. and Ochogavía A. C.; Supervision, Picardi L. and Nestares G. M.

\section{REFERENCES}

Abramoff, M. D., Magalhães, P. J. and Ram, S. J. (2004). Image Processing with ImageJ. Biophotonics International, 11, 36-42.

Baghali, Z., Majd, A., Chehregani, A., Pourpak, Z., Ayerian, S. and Vatanchian, M. (2011). Cytotoxic effect of benzo(a)pyrene on development and protein pattern of sunflower pollen grains. Toxicology \& Environmental Chemistry, 93, 665-677. https://doi.org/10.1080/02772248.2011.560851 Balabanova, D., Remans, T., Vasilev, A., Cuypers, A. and Vangronsveld, J. (2018). Possible involvement of glutathione S-transferases in imazamox detoxification in an imidazolinone-resistant sunflower hybrid. Journal of Plant Physiology, 221, 62-65. https://doi.org/10.1016/j.jplph.2017.12.008

Breccia, G., Vega, T., Felitti, S., Picardi, L. and Nestares, G. (2013). Differential expression of acetohydroxyacid synthase genes in sunflower plantlets and its response to imazapyr herbicide. Plant Science, 208, 28-33. https://doi.org/10.1016/j.plantsci.2013.03.008

Breccia, G., Gil, M., Vega, T., Altieri, E., Bulos, M., Picardi, L. and Nestares, G. (2017). Contribution of non-target-site resistance in imidazolinoneresistant Imisun sunflower. Bragantia, 76, 1-7. https://doi.org/10.1590/1678-4499.2016.336

Bruniard, J. M. and Miller, J. F. (2001). Inheritance of imidazolinone-herbicide resistance in sunflower. Helia, 24, 11-16.

Burd, M. (1994). Bateman's principle and plant reproduction: the role of pollen limitation in fruit and seed set. The Botanical Review, 60, 83-139.

Castaño, F. D. (2018). The sunflower crop in Argentina: past, present and potential future. Oilseeds and Fats, Crops and Lipids, 25, 1-10. https:// doi.org/10.1051/ocl/2017043

Cruden, R. W. (1977). Pollen-ovule ratios: a conservative indicator of breeding systems in flowering plants. Evolution, 31, 32-46. https://doi. org/10.2307/2407542

Herr Jr., J. M. (1971). A new clearing-squash technique for the study of ovule development in angiosperms. American Journal of Botany, 58, 785-790. https://doi.org/10.2307/2441475

Horner Jr., H. T. (1977). A comparative light- and electron-microscopic study of microsporogenesis in male-fertile and cytoplasmic male-sterile sunflower (Helianthus annuus). American Journal of Botany, 64, 745-759. https://doi.org/10.2307/2441727 
Horner Jr., H. T. and Pearson, C. B. (1978). Pollen wall and aperture development in Helianthus annuus (Compositae: Heliantheae). American Journal of Botany, 65, 3, 293-309. https://doi.org/10.2307/2442270

Kolkman, J. M., Slabaugh, M. B., Bruniard, J. M., Berry, S., Bushman, B. S., Olungu, C., Maes, N., Abratti, G., Zambelli, A., Miller, J. F., Leon, A. and Knapp, J. S. (2004). Acetohydroxyacid synthase mutations conferring resistance to imidazolinone or sulfonylurea herbicides in sunflower. Theoretical and Applied Genetics, 109, 1147-1159. https://doi.org/10.1007/s00122-004-1716-7

Laveau, J. H., Schenider, C. and Berville, A. (1989). Microsporogenesis abortion in cytoplasmic male sterile plants from H. petiolaris or H. petiolaris fallax crossed by sunflower (Helianthus annuus). Annals of Botany, 64, 2, 137-148. https://doi.org/10.1093/oxfordjournals.aob.a087817 Lersten, N. R. and Curtis, J. D. (1988). Secretory reservois (ducts) of two kinds in giant ragweed (Ambrosia trifida; Asteraceae). American Journal of Botany, 75, 1313-1323. https://doi.org/10.2307/2444454

Li, H., Li, J., Zhao, B., Wang, J., Yi, L., Liu, C., Wu, J., King, G. J. and Liu, K. (2015). Generation and characterization of tribenuron-methyl herbicideresistant rapeseed (Brasscia napus) for hybrid seed production using chemically induced male sterility. Theoretical and Applied Genetics, 128, 107-118. https://doi.org/10.1007/s00122-014-2415-7

Lian, J., Ren, L., Zhang, C., Yu, C., Huang, Z., Xu, A. and Dong, J. (2019). How exposure to ALS-inhibiting gametocide tribenuron-methyl induces male sterility in rapeseed. BMC Plant Biology, 19, 1-22. https://doi.org/10.1186/s12870-019-1722-1

Liu, X.-Q., Yu, C.-Y., Dong, J.-G., Hu, S.-W. and Xu, A.-X. (2017). Acetolactate synthase-inhibiting gametocide amidosulfuron causes chloroplast destruction, tissue autophagy and elevation of ethylene release in rapeseed. Frontiers in Plant Science, 8, 1-20. https://doi.org/10.3389/ fpls.2017.01625

Lv, J., Huang, Q., Sun, Y., Qu, G., Guo, Y., Zhang, X., Zhao, H. and Hu, S. (2018). Male sterility of an AHAS-mutant induced by tribenuron-methyl solution correlated with the decrease of ahas activity in Brassica napus L. Frontiers in Plant Science 9, 1-14. https://doi.org/10.3389/fpls.2018.01014

Maneval, W. E. (1936). Lacto-phenol preparations. Stain Technolology 11, 9-11. https://doi.org/10.3109/10520293609111316

Miller, J. F. and Al-Khatib, K. (2002). Registration of imidazolinone herbicide-resistant sunflower manteiner (HA 425) and fertility restorer (RHA 426 and RHA 427) germplasms. Crop Science 42, 988-989. https://doi.org/10.2135/cropsci2002.988a

Ochogavía, A. C., Novello, M. A., Bianchi, M. B., Picardi, L. and Nestares, G. M. (2018). Partial male sterility in imisun sunflower: imazapyr treatment in advanced vegetative stages decreases pollen yield and alters ahas gene expression. Crop Science, 58, 1877-1889. https://doi. org/10.2135/cropsci2017.12.0726

Ochogavía, A. C., Novello, M. A., Picardi, L. and Nestares, G. M. (2017). Identification of suitable reference genes by quantitative real-time PCR for gene expression normalization in sunflower. Plant Omics Journal, 10, 210-218. https://doi.org/10.21475/poj.10.04.17.pne831

Ochogavía, A. C., Breccia, G., Vega, T., Felitti, S. A., Picardi, L. A. and Nestares, G. (2014). Acetohydroxyacid synthase activity and transcripts profiling reveal tissue-specific regulation of ahas genes in sunflower. Plant Science, 224,144-150. https://doi.org/10.1016/j.plantsci.2014.04.018

Pacini, E., Franchi, G. and Hesse, M. (1985) The tapetum: Its form, function and possible phylogeny in Embryophyta. Plant Systematics and Evolution, 149, 155-185. https://doi.org/10.1007/BF00983304

Qian, H., Wang, R., Hu, H., Lu, T., Chen, X., Ye, H., Liu, W. and Fu, Z. (2011). Enantioselective phytotoxicity of the herbicide imazethapyr and its effect on rice physiology and gene transcription. Environmental Science \& Technology, 45,, 7036-7043. https://doi.org/10.1021/es200703v

R Development Core Team (2015). R: a language and environment for statistical computing. Vienna: R Foundation for Statistical Computing.

Sala, C. A. and Bulos, M. (2012). Use of imidazolinone tolerance to produce male-sterile testers in sunflower breeding programs. In: Proccedings of 18th International Sunflower Conference, Mar del Plata \& Balcarce, Argentina.

Sala, C. A., Bulos, M., Altieri, E. and Ramos, M. L. (2012). Genetics and breeding of herbicide tolerance in sunflower. Helia, 35, 57-70. https:// doi.org/10.2298/hel1257057s 
Schneiter, A. A. and Miller, J. F. (1981). Description of sunflower growth stages. Crop Science, 21, 901-903. https://doi.org/10.2135/ cropsci1981.0011183X002100060024x

Seiler, G. J., Qi, L. L. and Marek, L. F. (2017). Utilization of sunflower crop wild relatives for cultivated sunflower improvement. Crop Science, 57, 1083-1101. https://doi.org/10.2135/cropsci2016.10.0856

Qian, H., Li, Y., Sun, C., Lavoie, M., Xie, J., Bai, X. and Fu, Z. (2015). Trace concentrations of imazethapyr (IM) affect floral organs development and reproduction in Arabidopsis thaliana: IM-induced inhibition of key genes regulating anther and pollen biosynthesis. Ecotoxicology, 24 , 163-171. https://doi.org/10.1007/s10646-014-1369-5

Zhao, L., Jing, X., Chen, L., Liu, Y., Su, Y., Liu, T., Gao, G., Yi, B., Wen, J., Ma, C., Tu, J., Zou, J., Fu, T. and Shen, J. (2015). Tribenuron-methyl induces male sterility through anther-specific inhibition of acetolactate synthase leading to autophagic cell death. Molecular Plant, 8, 1710-1724. https:// doi.org/10.1016/j.molp.2015.08.009

\section{SUPPLEMENTARY MATERIAL}

ESM1. Environmental variables recorded during six hours after treatment by the Agrometeorological Station of the Facultad de Ciencias Agrarias de la Universidad Nacional de Rosario.

\section{Electronic Supplementary Material 1: Environmental variables recorded during the 6 hours after treatment by the Agrometeorological Station of the FCA-UNR}

Herbicide application schedule: $\quad$ 2017-11-30 10:30 a.m.

Agrometeorological station location: Facultad de Ciencias Agrarias-UNR, Parque Villarino S/N,

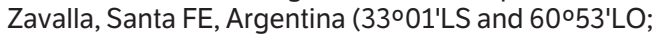
altitude $50 \mathrm{~m}$ above sea level)

\begin{tabular}{|c|c|c|c|c|c|}
\hline Hour & $\begin{array}{l}\text { Atmospheric pressure } \\
(\mathrm{hPa})\end{array}$ & $\begin{array}{l}\text { Wind speed } \\
\qquad(\mathrm{Km} / \mathrm{h})\end{array}$ & $\begin{array}{c}\text { Air temperature } \\
\left({ }^{\circ} \mathrm{C}\right)\end{array}$ & $\begin{array}{l}\text { Air Humidity } \\
(\%)\end{array}$ & $\begin{array}{c}\text { Solar } \\
\text { Radiation } \\
\text { (w/m2) }\end{array}$ \\
\hline 10:30:00 & 1005.60 & 16.80 & 27.50 & 50.00 & 619.00 \\
\hline 10:45:00 & 1005.60 & 15.90 & 27.80 & 50.00 & 649.00 \\
\hline $11: 00: 00$ & 1005.50 & 14.10 & 28.80 & 50.00 & 677.00 \\
\hline $11: 15: 00$ & 1005.40 & 16.90 & 28.50 & 47.00 & 701.00 \\
\hline $11: 30: 00$ & 1005.40 & 15.50 & 28.70 & 48.00 & 725.00 \\
\hline $11: 45: 00$ & 1005.20 & 15.00 & 28.90 & 47.00 & 742.00 \\
\hline $12: 00: 00$ & 1005.10 & 15.20 & 29.80 & 47.00 & 758.00 \\
\hline $12: 15: 00$ & 1004.90 & 15.10 & 29.70 & 43.00 & 771.00 \\
\hline $12: 30: 00$ & 1004.70 & 14.50 & 30.00 & 43.00 & 779.00 \\
\hline $12: 45: 00$ & 1004.70 & 14.60 & 30.30 & 40.00 & 784.00 \\
\hline $13: 00: 00$ & 1004.50 & 14.40 & 31.10 & 36.00 & 787.00 \\
\hline 13:15:00 & 1004.40 & 12.80 & 31.30 & 38.00 & 785.00 \\
\hline $13: 30: 00$ & 1004.20 & 14.20 & 31.00 & 40.00 & 775.00 \\
\hline $13: 45: 00$ & 1004.10 & 14.10 & 31.90 & 39.00 & 765.00 \\
\hline 14:00:00 & 1004.00 & 14.60 & 31.30 & 40.00 & 749.00 \\
\hline 14:15:00 & 1003.90 & 14.00 & 32.00 & 38.00 & 732.00 \\
\hline $14: 30: 00$ & 1003.60 & 14.30 & 32.10 & 36.00 & 713.00 \\
\hline $14: 45: 00$ & 1003.50 & 15.80 & 32.20 & 35.00 & 693.00 \\
\hline 15:00:00 & 1003.30 & 16.20 & 31.90 & 39.00 & 668.00 \\
\hline $15: 15: 00$ & 1003.20 & 18.50 & 31.90 & 36.00 & 637.00 \\
\hline $15: 30: 00$ & 1003.10 & 17.40 & 31.90 & 34.00 & 608.00 \\
\hline $15: 45: 00$ & 1003.00 & 14.00 & 32.00 & 34.00 & 577.00 \\
\hline $16: 00: 00$ & 1002.80 & 15.30 & 32.30 & 34.00 & 544.00 \\
\hline $16: 15: 00$ & 1002.70 & 15.40 & 32.00 & 35.00 & 510.00 \\
\hline $16: 30: 00$ & 1002.50 & 16.00 & 32.10 & 35.00 & 471.00 \\
\hline MEAN & 1004.20 & 15.22 & 30.68 & 40.56 & 688.76 \\
\hline
\end{tabular}



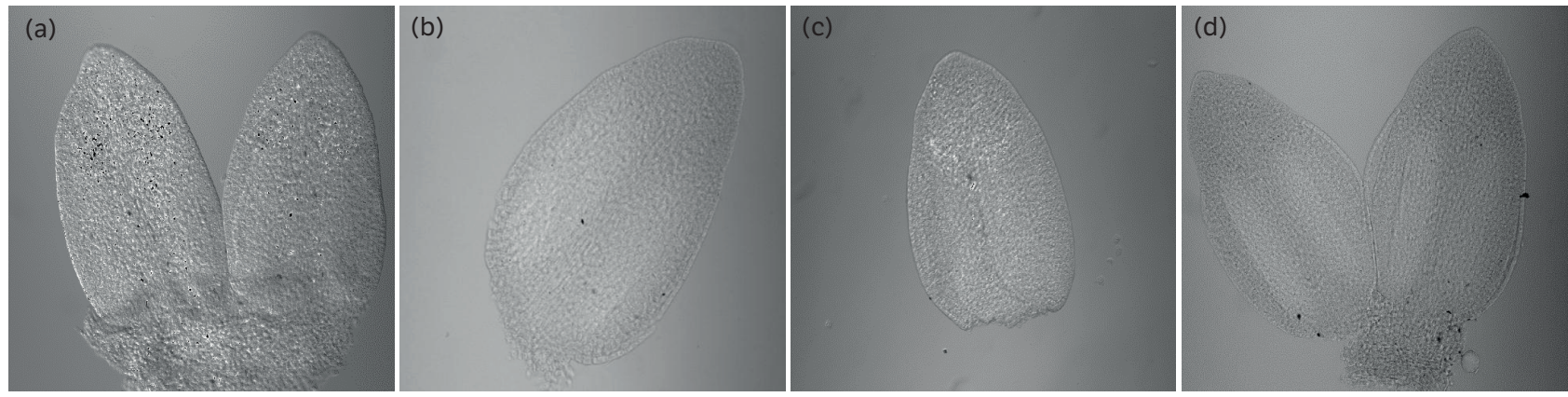

ESM2. DIC micrographs of immature anthers collected from peripheral flower buds at 11 days after IM-treatments (1X and 2X) of HA425(R) and 1058-1(I) genotypes. 